\title{
WORKFORCE INFORMATION DATABASE SYSTEM TO SUPPORT PRODUCTION PLANNING IN CONSTRUCTION PROJECTS
}

\author{
Sang-Chul Kim ${ }^{1}$, Yong-Woo Kim ${ }^{2}$ \\ ${ }^{1}$ Hanbat National University - Architectural Engineering, Daejon, Republic of Korea \\ ${ }^{2}$ University of Washington - Construction Management, Box 351610120 Arch Hall, Seattle, \\ Washington 98195, United States \\ E-mails: ${ }^{1}$ harvard9@naver.com; ${ }^{2}$ yongkim@u.washington.edu (corresponding author) \\ Received 05 Apr. 2011; accepted 02 Nov. 2011
}

\begin{abstract}
Information on the capacity of available workforce is important in production planning because a production unit's quantitative and qualitative capacities need to match its assigned loads. In the planning process, assigned loads and quantitative capacity are well defined quantitatively through quantity takeoff and database estimation. However, tracking and managing such workforce information, including skills, accident history and experiences, is a challenging task. This research seeks to develop a prototype workforce information database system that defines not only quantitative data but also qualitative measures in relation to load and capacity. A workforce information database system is described for use in workforce-level production planning. This database system tracks the daily quantitative and qualitative production capacities of each worker. The paper also explored the benefits and its applicability in production planning through a survey.
\end{abstract}

Keywords: workforce information database, production planning, mobile computing technology (MCT), radio-frequency identification (RFID) technology.

\section{Introduction}

Production planning spans from a master schedule to look-ahead and weekly work plans. While a master schedule is used as a strategic planning tool, the lookahead and weekly work plans are used as production planning tools (Ballard 2000). Many models (Adeli, Karim 1997; AbouRizk, Mather 1998; Sucur, Grobler 1996; Aalami 1998) suited for developing a master schedule for a project and creating the list of required activities have been developed, along with preferred precedence relationships between activities under expected constraints. A large number of computer tools have also been developed to assist project managers in manually developing and maintaining a master schedule. They function as tools for generating a common representation that depicts predecessor relationships between activities where each activity has a given duration and unit resources allocated to it. This representation facilitates communication between different participants involved in a construction project as to who should be doing which work and when.

However, these tools are inadequate when it comes to supporting production planning, which in turn is the primary tool of personnel performing construction work in the field. The productivity of field workers depends mainly on the actual availability of resources and the crew's actual capacity. Availability of resources is governed by resource flow prior to installation, including the timely generation or procurement, release or delivery, and allocation of their resources (Tommelein, Ballard 1997; Choo 2003). The Last Planner System (LPS) and relevant computer tools enables the production planning process to ensure availability of resources on time by shielding uncertainties from flowing into production units (Ballard et al. 2007; Kim et al. 2008a).

The capacity of crews or production units in production planning needs to be updated as soon as information becomes available. In the planning process, assigned loads and quantitative capacity are well defined quantitatively through quantity takeoff and database estimation, whereas a production unit's qualitative capacity could not be easily tracked or managed. The performance quality of a certain production unit can be defined using various qualitative attributes such as the level of workmanship, accident history and experiences. The capacity of crews or production units taking into account their qualitative attributes is important in improving production plan quality, but this information is hard to acquire in managing construction projects.

In recent years, mobile computing technologies (MCT) such as radio-frequency identification (RFID) and personal digital assistants (PDA) are being adopted to transmit a variety of information among project participants. Those technologies contributed to improving field work, consequently reducing construction duration, defects, accidents and wastes (Kimoto et al. 2005; Bowden et al. 2006). MCT can facilitate the easy transmission of knowledge and expertise to field workers as well as field information to management. With MCT, the information on production units (e.g., qualitative attributes of production units) could be easily collected and transmitted so 
that such information could be updated and reflected in the production plan.

This paper proposes a method of developing and identifying qualitative attributes to complement historic data-based quantitative capacity, which helps improve the quality of the production planning process. A prototype database system with the qualitative attributes of production units is also presented to help production planners (i.e., project engineers or supervisors) match the capacity of production units with workloads more efficiently. The research approach to this end can be best explained by identifying the different research phases and tasks as follows (Fig. 1).

The first phase of the research involved several rounds of literature review and discussions with industry professionals. This phase sought to understand current production planning practice in terms of matching capacity and load and how mobile communication technology is being utilized in construction projects.

The development of system architecture and prototype database system is then examined. The research team conducted a survey to identify major factors in determining a production unit's qualitative capacity. The number of respondents was 136 practitioners. After identifying needs (i.e., factors in workforce capacity), the research team developed a workforce information database system prototype coupled with MCT to collect, track, and manage workforce information to be used in calculating capacity.

A pilot project for testing the proposed prototype system was implemented. The pilot test demonstrated how the system can help field engineers and site managers use quantitative and qualitative information on loads and capacity in production planning. In order to validate the proposed system's usability, a survey was performed on foremen, superintendents, field engineers, and site managers. The potential benefits from interpreting survey results were described in the Discussion section.

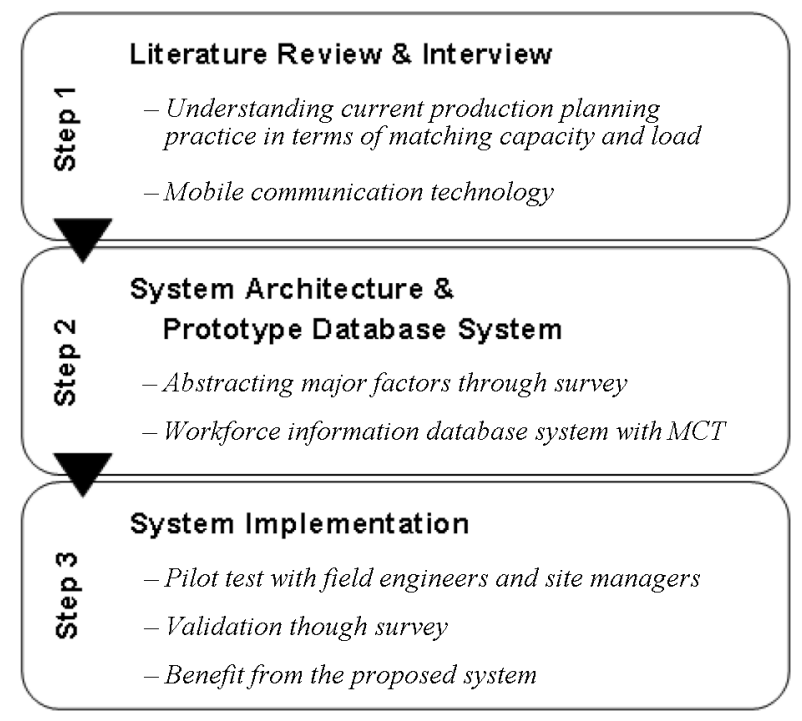

Fig. 1. Research method

\section{Matching capacity and load production planning}

Project planning techniques based on network models (such as CPM) are currently accepted and applied. However, such project scheduling techniques are not effective in managing production based on the schedule (Choo 2003). Superintendents and foremen use some form of production planning tool to execute their projects. In many cases, these tools were neither systemized nor formalized. Production planning is the most detailed planning process developed by foremen of contractors who will actually carry out the work (Ballard 1994; Ballard, Howell 1998). The production units (e.g., subcontractor) can provide knowledge regarding: (1) development of creative solutions; (2) space needs; (3) construction capacities; and (4) supplier's lead-times and reliability (Gil et al. 2000). Production planning attempts to match capacity and assignment load with optimal precision based on given conditions (Ballard et al. 2007). Information regarding work force capacity includes availability of labor, equipment, and tools. In terms of labor, information includes the skill level, productivity, and availability of each worker. However, such labor information is hard to quantify and track, giving rise to problems in leveraging such information in production planning (Choo 2003). A recent survey (Viana et al. 2010) indicated that this lack of information is one of the critical challenges encountered in implementing a production plan on construction sites.

Matching load to capacity in a production planning system is critical in determining productivity of the production units (Ballard, Howell 1998; Ballard 2000), and is also integral to system cycle time, the time required for something to go from one end to the other (Ballard 2000). A production planner needs information not only regarding assignment or work task loads but also regarding resource capacity as shown in Fig. 2.

Work task loads and resource capacity may be assessed both quantitatively and qualitatively. When focusing on quantity, load is the amount of work within a specific time that is assigned through planning, and capacity is the amount of work a crew (or production unit) can perform during the planning span given specific tools and work methods under site conditions. Quantitative assessment can be represented in work quantity per resource volume, e.g., painting 30 square feet/man-hour) (Holm et al. 2004). Estimating references such as R.S. Means and customized estimating database use the quantitative approach in accessing work task loads and resource capacity. However, current estimating unit rates, such as the labor hours required to place a cubic yard of concrete, are at best averages based on historical data. Such data are themselves laden with the tremendous amounts of waste imbedded in conventional practice (Ballard 2000). Real and estimated values can differ largely depending on many variables such as site conditions and actual work force configuration. In other words, current quantitative assessment contains a high level of uncertainty.

On the other hand, the qualitative approach deals with the quality of resources and how work tasks are 


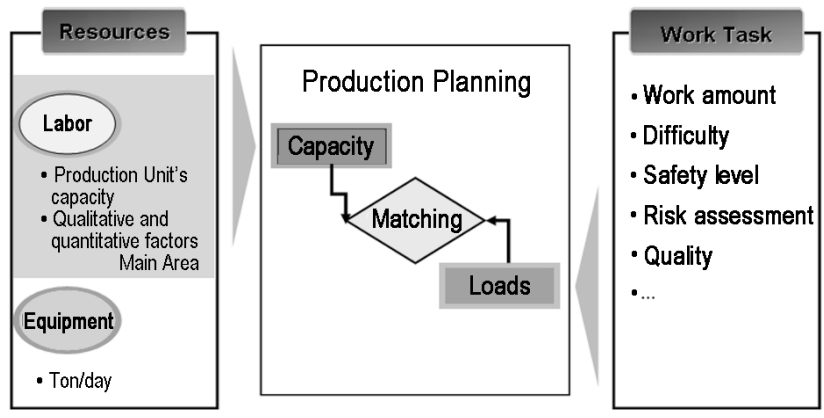

Fig. 2. Production planning mechanism

performed. When focusing on the quality approach, load can be any required work tasks in the actual site conditions. For example, some work tasks would require that workers be educated first about a special safety requirement. Capacity in this approach refers to the qualitative capability of a crew such as experiences and safety records.

Whatever the accuracy of load and capacity estimates is, the planner must still make some adjustments by taking into account qualitative factors such as actual site conditions. After adjusting the load and capacity, either load can be changed to match capacity, capacity can be changed to match load, or, more commonly, a combination of the two (Ballard 2000). However, matching load with capacity using the qualitative approach is still difficult to achieve. In many cases, information on workforce capacity remains unavailable in production planning for several reasons. For example, the level of workmanship is difficult to track and manage even in cases when labor turnover rate is high. However, information on the quality work tasks and capacity is important in matching work task loads with resource capacity during production planning. This research uses a database coupled with RFID technology in order to track and maintain load and capacity information in both quantitative and qualitative approaches. This paper shows how to assess work tasks and capacity in both approaches, though which we pursue more accurate matching of load with capacity.

\section{Mobile communication technology}

This research uses mobile communication technology to track data. The applications of RFID, which is one of the key devices in MCT, are the essential components in the processes undertaken by the construction industry. Many research projects have shown the benefits of RFID applications including in concrete operations, personnel management, productivity analysis, construction tool tracking and pipe spool tracking (Jaselskis et al. 1995; Jaselskis, El-Misalami 2003; Song et al. 2006a). RFID is one of the important automatic identification techniques currently being used in many industries. The RFID tag is a small wireless computer chip that could be embedded into almost any product. It uses an on-board microprocessor and an antenna to wirelessly transmit and receive certain information uniquely related to the item. The RFID tag uses a small and inexpensive passive tag with an unlimited life cycle.
Recently, several attempts have been made in applying RFID technology to the construction industry. Ergen et al. (2007) suggested using RFID in facility management. Tests have been conducted in order to determine the technological feasibility of RFID within a facility on a daily basis with active RFID (Sarma, Engels 2003). Song et al. (2006b) evaluated the use of RFID technology in tracking pipe spools through a long supply chain. Through his pilot studies, Schneider (2003) asserted that RFID is an effective method in reducing project activity time and cutting project costs.

PDAs, on the other hand, comprise one of the stateof-the-art technologies in MCT that have appeared on site application in recent years. Kimoto et al. (2005) describes aim, concept based on End User Computing, and the essential element of the mobile system as well as the structure of the system and outline of subsystems. Chen et al. (2002) suggested that the PDA can collect information in real time and makes available this information for analysis the next day. Also, Burgy and Garrett (2002) insists that mobile computing can eliminate and/or decrease the gap between outdoor construction site and the indoor office. Construction managers may effectively use digital data input using the mobile computing device on the construction site. Kim et al. (2008b) presented a computerized Quality Inspection and Defect Management System (QIDMS) that can collect defect data at a site in real time using a Personal Digital Assistant (PDA) and wireless internet. Wang (2008) and Kim et al. (2008b) showed the advantage of adopting online portals and mobile devices in the quality inspection process. Kim et al. (2011) adopted RFID while the ZigBee protocol was tested in an indoor environment for monitoring construction material. RFID was used in another research (Moon, Yang 2010) to improve communications during concrete pouring operations.

Most of the recent articles have emphasized how IT can effectively be activated in construction sites to help improve the quality and efficacy of construction work. However, no research work has been conducted on the use of IT on production planning, especially with regard to gathering exact information about workforce capacity.

The above papers show that the use of RFID and PDA can benefit the construction industry with applications in various management areas such as materials management, tracking of tools and equipment, automated equipment control, jobsite security, maintenance and service, document control, failure prevention, quality control, field operations and construction safety.

\section{Assignment loads}

To define assigned loads, contractors observe the following processes: quantity takeoff, calculating how crew numbers of each production unit would execute each work task and assessment.

\subsection{Quantity takeoff}

Quantity takeoff is one of the most important processes during pre-construction. If the amount and costs of con- 
struction materials are lower or higher than optimal, a contractor may fail. Also, if contractors, upon calculating quantity takeoff, do not know their own productivity such as workforce and equipment productivity, they may encounter much difficulty. Therefore, big or small contractors maintain not only their own quantity takeoff guidelines and database but also productivity database. The following table is an actual productivity data used in an actual Korean construction company (Quantity takeoff guideline and DB are not included in this paper).

\subsection{Quantitative production unit capacity}

After obtaining quantity takeoff, contractors usually calculate how many people and equipment will be involved in the project. A sample calculation for a condominium project is presented below:

- Form work: $648 \mathrm{~m}^{2}$;

- Rebar work: 8 ton;

- Concrete: $180 \mathrm{~m}^{3}$.

From the workforce productivity database, a contractor can easily find the exact figures in Table 1 . Similarly, a contractor can find information related to duration per floor from their database (see C. Duration per floor). Using duration per floor, contractors can acquire the figures (see D. Amount per duration). Contractors could then determine exactly how many workers are needed in building one condominium floor (see E. Calculation workforce per day). Below, Table 2 shows how many workers are needed in each work: form workers -6 ; rebar workers -4 ; and concrete workers -3 . Contractors can then select workers based on the exact information.

Table 1. Manpower productivity in condominium project

\subsection{Work task assessment}

After contractors devise a master schedule, a monthly schedule, and a weekly schedule, contractors or subcontractors in the field can imagine which work task needs to be constructed for a given week or day. Subsequently, they could correctly begin to assess risks. As in Fig. 3, they input figures according to how difficult or dangerous the work tasks are. An assessment could determine levels of difficulty according to impact and occurrences: Level 1 is no risk; Level 2 - low risk; Levels 3-4 - middle level; Level 5 - high risk; and Level 6 - extremely high risk. The Figure shows an example of "Scaffolding and Wire Mesh" related to work task assessment. If a work task was

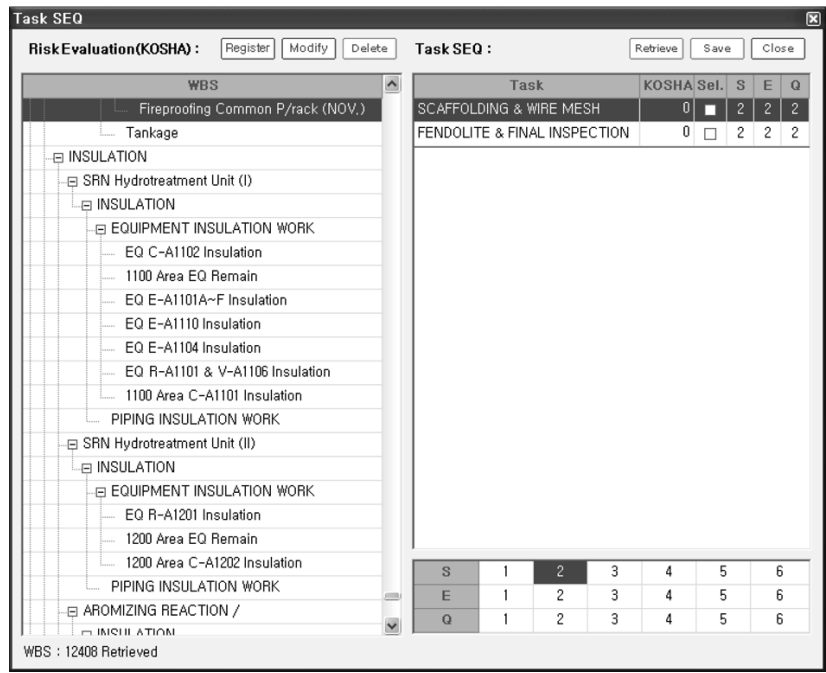

Fig. 3. Work task assessment

\section{Workforce Productivity}

\begin{tabular}{|c|c|c|c|c|}
\hline Classify & Attribute & Activity & Unit & Average (1day) \\
\hline \multirow[t]{2}{*}{ Scaffolding } & & Dismantle scaffolding (Double) & $\mathrm{m}^{2}$ & 57.6 \\
\hline & & Dismantle scaffolding (Single) & $\mathrm{m}^{2}$ & 117.3 \\
\hline \multirow[t]{2}{*}{ Form } & Parking lot & R.C structure & $\mathrm{m}^{2}$ & 18.3 \\
\hline & Condo & R.C structure & $\mathbf{m}^{2}$ & 27.0 \\
\hline \multirow[t]{2}{*}{ Rebar } & Parking lot & R.C structure & ton & 1.4 \\
\hline & Condo & R.C structure & ton & 1.0 \\
\hline \multirow[t]{2}{*}{ Concrete } & Parking lot & R.C structure & $\mathrm{m}^{3}$ & 66.4 \\
\hline & Condo & R.C structure & $\mathrm{m}^{3}$ & 50.8 \\
\hline Brick & & Brick & EA & $1,585.7$ \\
\hline \multirow[t]{2}{*}{ Plastering } & Parking lot & Plastering & $\mathrm{m}^{2}$ & 42.1 \\
\hline & Condo & Plastering & $\mathrm{m}^{2}$ & 32.9 \\
\hline \multirow[t]{2}{*}{ Water proofing } & Parking lot & Water proofing & $\mathrm{m}^{2}$ & 48.3 \\
\hline & Condo & Water proofing & $\mathrm{m}^{2}$ & 36.7 \\
\hline \multirow[t]{2}{*}{ Tile } & & Tile in floor & $\mathrm{m}^{2}$ & 19.4 \\
\hline & & Tile in wall & $\mathrm{m}^{2}$ & 18.0 \\
\hline \multirow[t]{4}{*}{ Stone } & & Stone in washroom's wall & $\mathrm{m}^{2}$ & 3.6 \\
\hline & & Stone in washroom's floor & $\mathrm{m}^{2}$ & 3.9 \\
\hline & & Stone in entrance & $\mathrm{m}^{2}$ & 6.0 \\
\hline & & Exterior stone & $\mathrm{m}^{2}$ & 6.3 \\
\hline Glass & & Interior, exterior glass & $\mathrm{m}^{2}$ & 111.3 \\
\hline \multirow[t]{2}{*}{ Furniture } & & Closet in bedroom & Set & 23.0 \\
\hline & & Closet in entrance & Set & 21.0 \\
\hline
\end{tabular}


Table 2. Calculating production unit

Case Study

\begin{tabular}{|c|c|c|c|c|}
\hline A. Condition & Condominium & & & \\
\hline 1. Form & 648 & $\mathrm{~m}^{2}$ & & \\
\hline 2. Rebar & 8 & ton & & \\
\hline 3. Concrete & 180 & $\mathrm{~m}^{3}$ & & \\
\hline \multicolumn{5}{|l|}{ B. From DB } \\
\hline Form & Parking lot & R.C structure & $\mathrm{m}^{2}$ & 18.3 \\
\hline Rebar & $\begin{array}{l}\text { Condo } \\
\text { Parking lot } \\
\text { Condo } \\
\text { Parking lot }\end{array}$ & $\begin{array}{l}\text { R.C structure } \\
\text { R.C structure } \\
\text { R.C structure } \\
\text { R.C structure }\end{array}$ & $\begin{array}{l}\mathbf{m}^{2} \\
\text { ton } \\
\text { ton } \\
\mathrm{m}^{3}\end{array}$ & $\begin{array}{c}27.0 \\
1.4 \\
1.0 \\
66.4\end{array}$ \\
\hline Concrete & Condo & R.C structure & $\mathrm{m}^{3}$ & 50.8 \\
\hline \multicolumn{5}{|l|}{ C. Duration per floor } \\
\hline 1. Form workman & 4 & day/cycle & & \\
\hline 2. Rebar workman & 2 & day/cycle & & \\
\hline 3. Concrete workman & 1 & day/cycle & & \\
\hline \multicolumn{5}{|c|}{ D. Amount per duration } \\
\hline 1. Form workman & 162 & $\mathrm{~m}^{2} /$ day & $(648 / 4)$ & \\
\hline 2. Rebar workman & 4 & ton/day & $(8 / 2)$ & \\
\hline 3. Concrete workman & 180 & $\mathrm{~m}^{3} /$ day & $(180 / 1)$ & \\
\hline \multicolumn{5}{|c|}{ E. Calculating workforce per day } \\
\hline 1. Form workman & $162 / 27$ & 6 people & & \\
\hline 2. Rebar workman & $4 / 1$ & 4 people & & \\
\hline 3. Concrete workman & $180 / 50.8$ & 3 people & & \\
\hline
\end{tabular}

defined by the standards of the Korean Occupational Safety and Health Agency (KOSHA), that work task must follow guidelines that were set by KOSHA. S means safety, E means Environment, and Q means quality. Each work task has three different attributes, and contractors or subcontractors should assess them according to the risk level. If work task is classified Level 2 in terms of safety, environment and quality, contractors or subcontractors would issue a warning before construction work is done.

\subsection{Problems in selecting production units}

From the above tables and figure, contractors become aware of how many people will be involved in a work task and how difficult or dangerous construction will be. Because a construction project needs many people, contractors usually tend to choose not an individual person but an entire production unit. Subsequently, they face the real problem, which will be the right production unit for this project?

Though contractors can calculate the exact figure, if they do not have the right information about a production unit's capacity, they cannot be certain of their success. Therefore, they should first gather quantitative and qualitative information.

\section{Workforce Information Database System}

Though a production unit's capacity is important in production planning, construction managers and site managers are not aware which attributes of the production unit capacity are important in a workforce and how workforce capacity information on site can be gathered. This research, therefore, investigated which capacity is important based on a survey, and suggested a workforce information database system in order to collect workforce capacity information using RFID and PDA.

\subsection{Major factors in determining a production unit's qualitative capacity}

The authors surveyed 136 project engineers and managers to investigate what workforce information can be useful for production/safety planning and control. Table 3 shows the survey results. The system tracks and manages the following information:

- General personal information (age, nationality, passport number, workmanship);

- Safety records;

- Work experience and level of workmanship.

Therefore, in production planning design, contractors have to know a production unit's capacity, which depends on skill, experience and safety history. These three major factors are the basic elements that should be included in the workforce information database system for contractors. However, collecting, tracking and managing workforce information in the field is not easy, so this research adopts MCT, specifically RFID and PDA technologies. 
Table 3. Survey result on useful workforce information

\begin{tabular}{lcc}
\hline \multicolumn{1}{c}{ Information } & $\begin{array}{c}\text { No. of people who } \\
\text { chose the } \\
\text { information useful }\end{array}$ & $\begin{array}{c}\text { Percent- } \\
\text { age }\end{array}$ \\
\hline Job Classification & 124 & $93.9 \%$ \\
Accident record & 121 & $91.7 \%$ \\
Communication Skill & 54 & $40.9 \%$ \\
Level of Workmanship & 116 & $87.9 \%$ \\
Training record & 71 & $53.8 \%$ \\
Violation record & 89 & $67.4 \%$ \\
Work experience & 85 & $64.4 \%$ \\
\hline * Total number of respondents, 132; non-respondents, 4. \\
\hline
\end{tabular}

\subsection{System architecture in Workforce Information Database System}

A web-based version of the Workforce Information Database System that is mainly used by foremen, field engineers, superintendents, and site managers, has been recently developed. A simple database scheme, designed for workforce information databases, has been used. Fig. 4 illustrates the Entity Relation (ER) diagram for the databases, which shows the type of data and relationships between data. Tables regarding general information include data on personal information, eligibility of work and visa status. Tables regarding safety records include data on health, safety violation and training records. Tables regarding work history and workmanship include employment history, previous projects and level of workmanship.

\subsection{Description of Workforce Information Database System}

Information on a new worker who just arrived on site needs to be registered in the workforce information database system. Once registered, the worker receives a temporary ID embedded with a passive RFID tag. As the tag is scanned, the information is simultaneously sent to the workforce information database system. Front line mangers instantly get exact information on how many people come on site and when they arrive.

There are three methods of inputting workforce information into the database system. First is with the use of the RFID tag, which records when personnel arrive and leave. The second involves the use of the Internet on the site or at the headquarters office, which is the most common way used for information input. The last is by using PDA, a kind of web accessing device, that allows field engineers to instantly input all information about their workforce. This paper mainly focuses on the third method.

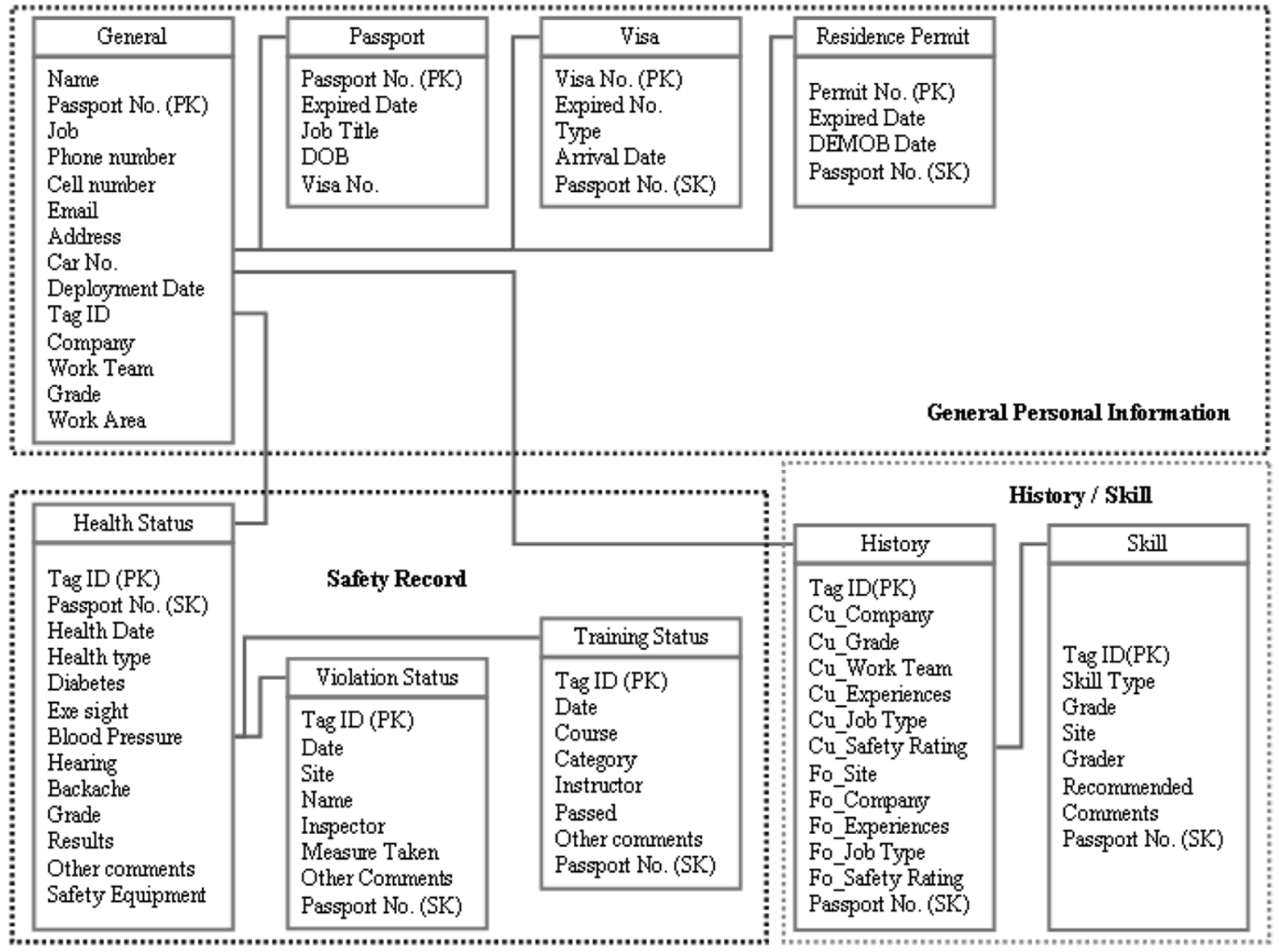

Fig. 4. Entity relation diagram for Workforce Information Database System 
The sample windows below show what information can be retrieved from the workforce information database system. Figs 5, 6 and 7 give actual screen dumps from the workforce information database system. Fig. 5 shows data input screens regarding general personal information. The Entry Form under the section "General" allows the user to enter information about their job, contact information, evidence of work eligibility and work location. In work location, a worker registers his or her company and work team (production unit). All this information will be applied to production planning.

In the same manner, information about safety records is entered using the data entry form as shown in Fig. 6. Three types of safety data, health status, safety violation and safety training status, are updated and managed in order to prevent accidents.
The database system also allows the user to enter work experience and the level of workmanship for each work as shown in Fig. 7. Level of workmanship is usually evaluated by field engineers or site managers. This grade can be referred to by the next project's field engineers, updated or modified. In many cases, however, such information is not properly managed and maintained. The workforce information database system builds a range of comprehensive information regarding each worker's capacity including the level of workmanship and safety records.

\subsection{RFID System}

RFID is the next wave in the evolution of computing. Employee ID cards with passive RFID tags are scanned by a reader when employees pass through the gate. The system operates at $13.56 \mathrm{MHz}$, taking into account the readable range required on sites (Fig. 8).

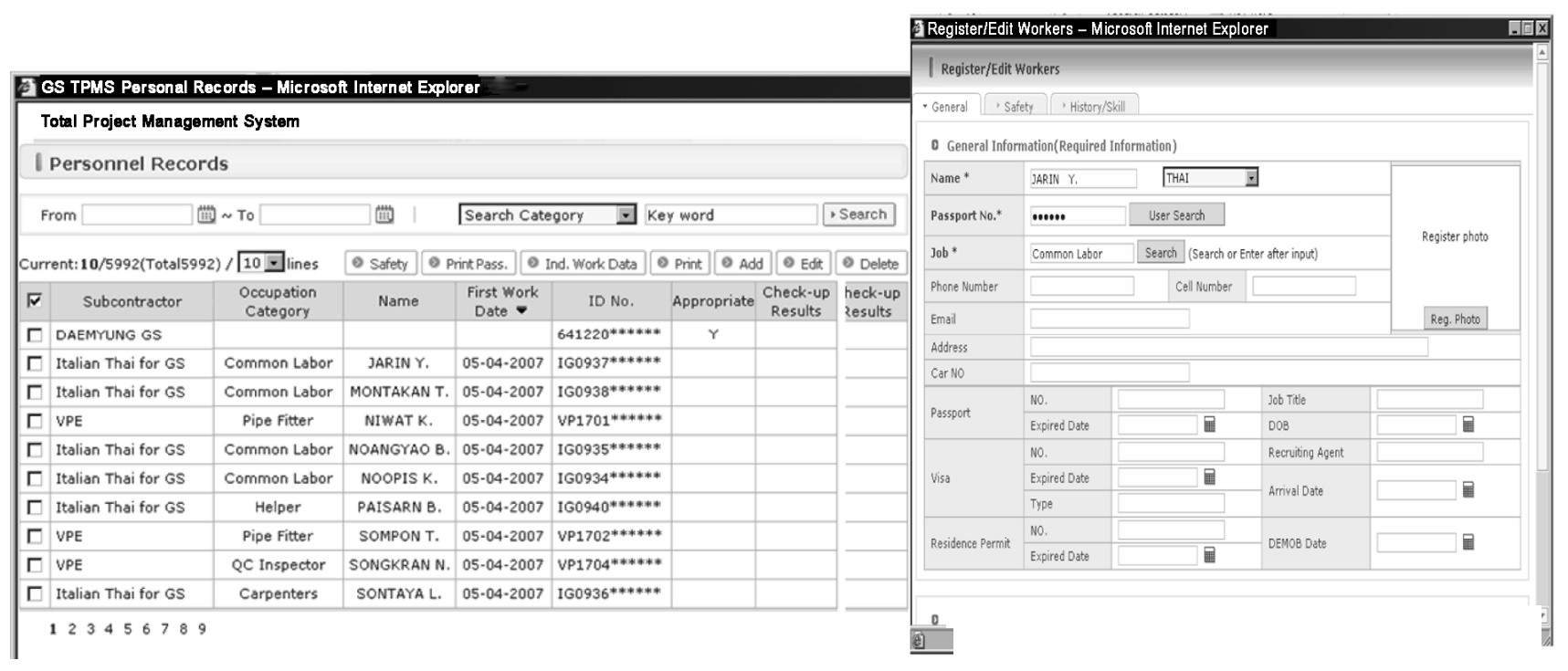

Fig. 5. Personal records window

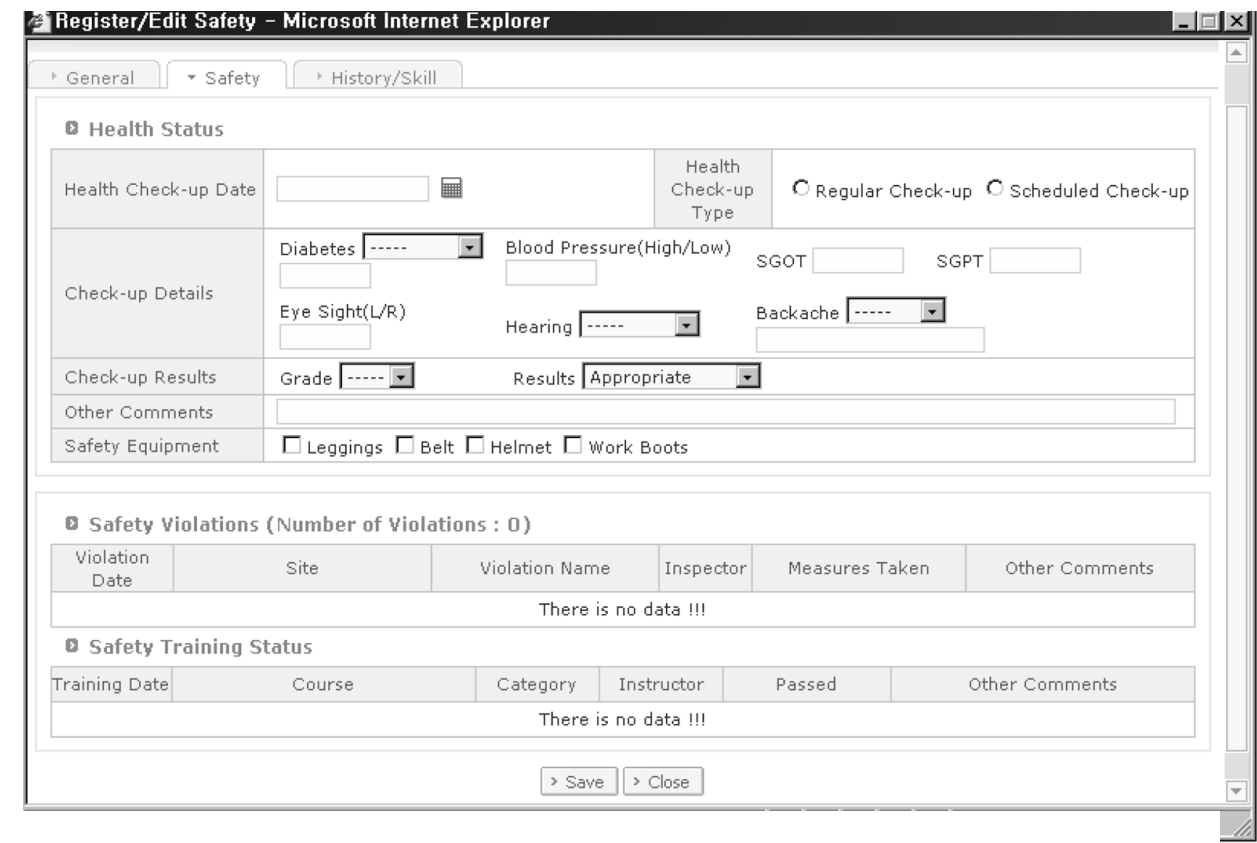

Fig. 6. Safety records window 


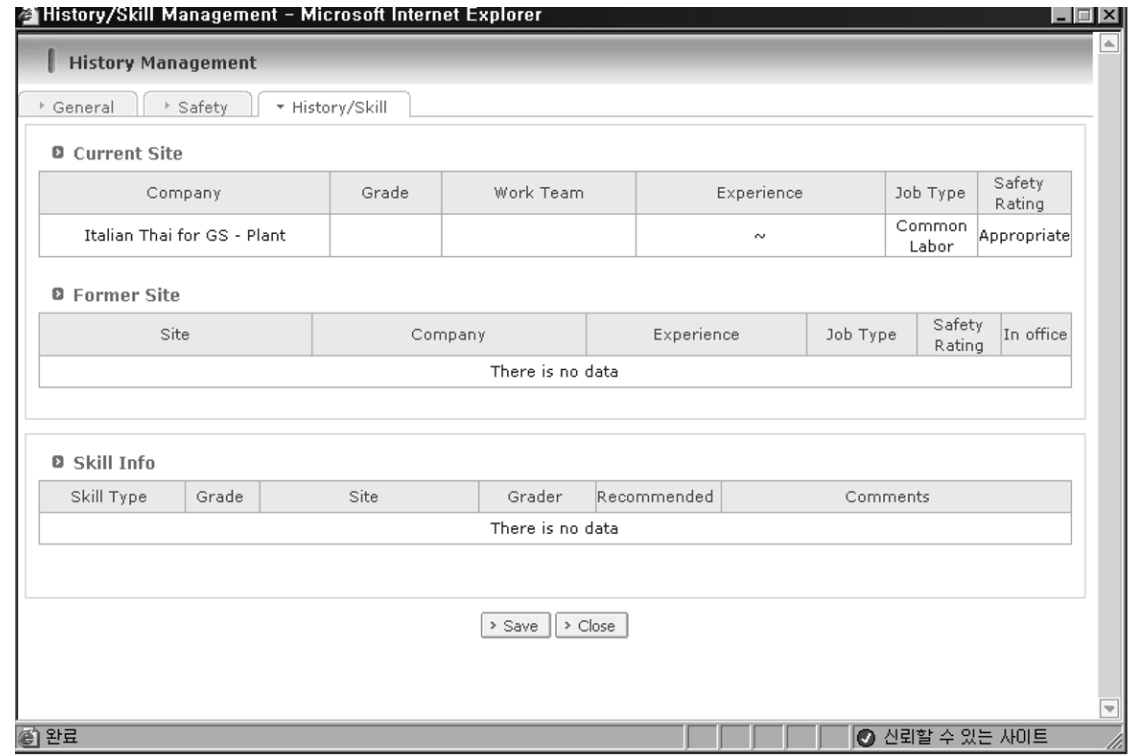

Fig. 7. History/Skill window

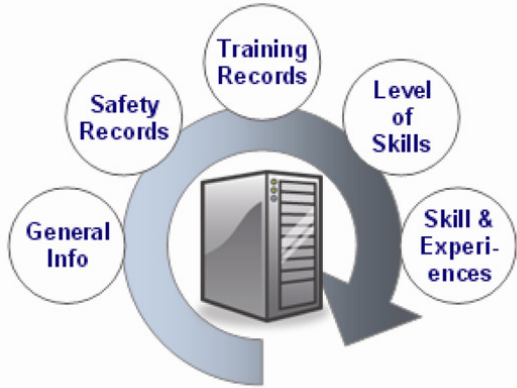

Workforce Information Database Server

- Search ID which is in agreement with received ID \& transmit the information to project engineers who requested it

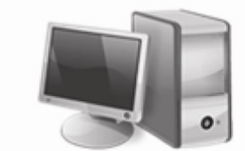

Terminal with Reader

Transmit ID information

to a database

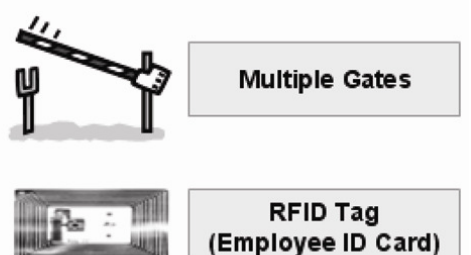

Transmit ID information at the entry of the site

Fig. 8. System architecture for RFID System

\subsection{Workforce Information Database System using PDA}

PDA is one of the most powerful devices in the construction site. Usually, a construction site area is wide or has so many layers such that the site office is far from field engineers.

The first window of the PDA has two major functions, Safety Violation (Fig. 9) and Personal records (Fig. 10). Using a PDA, field engineers can retrieve and input information on their workers. All the information in a PDA and in the workforce information database system is synchronized.

When field engineers click the Safety Violations button, they are directed to the Worker List window. Then, they select a team within the subcontractor and search the name of a worker, specifically selecting the one who violated a safety policy. The safety violation history of the selected worker shall then be displayed. Also, if the worker later commits another violation, a field engineer may choose a violating item and click on the Save button.

This shows how engineers and managers can input violation records simultaneously on site as well as how they can see workforce records about safety.

The next function is about personal records. The Personal Records Menu has 4 sub taps that include Basic, Safety, History and Skill. Each tab is synchronized with the workforce information database system windows, Figs 5, 6 and 7, respectively. Using the Basic tab, field engineers can refer to individual information on a worker's company. If they want to check someone's records, they will click on the button on the right side of Company, select a team, click on Search button for a worker's name and then select an option. If they click the Photo button, they can even see a worker's photo. In the second Safety tab, detailed information on safety violation history as well as safety training history of the person is referred to. In the third History tab, engineers and managers can view the past career of a worker in the current 

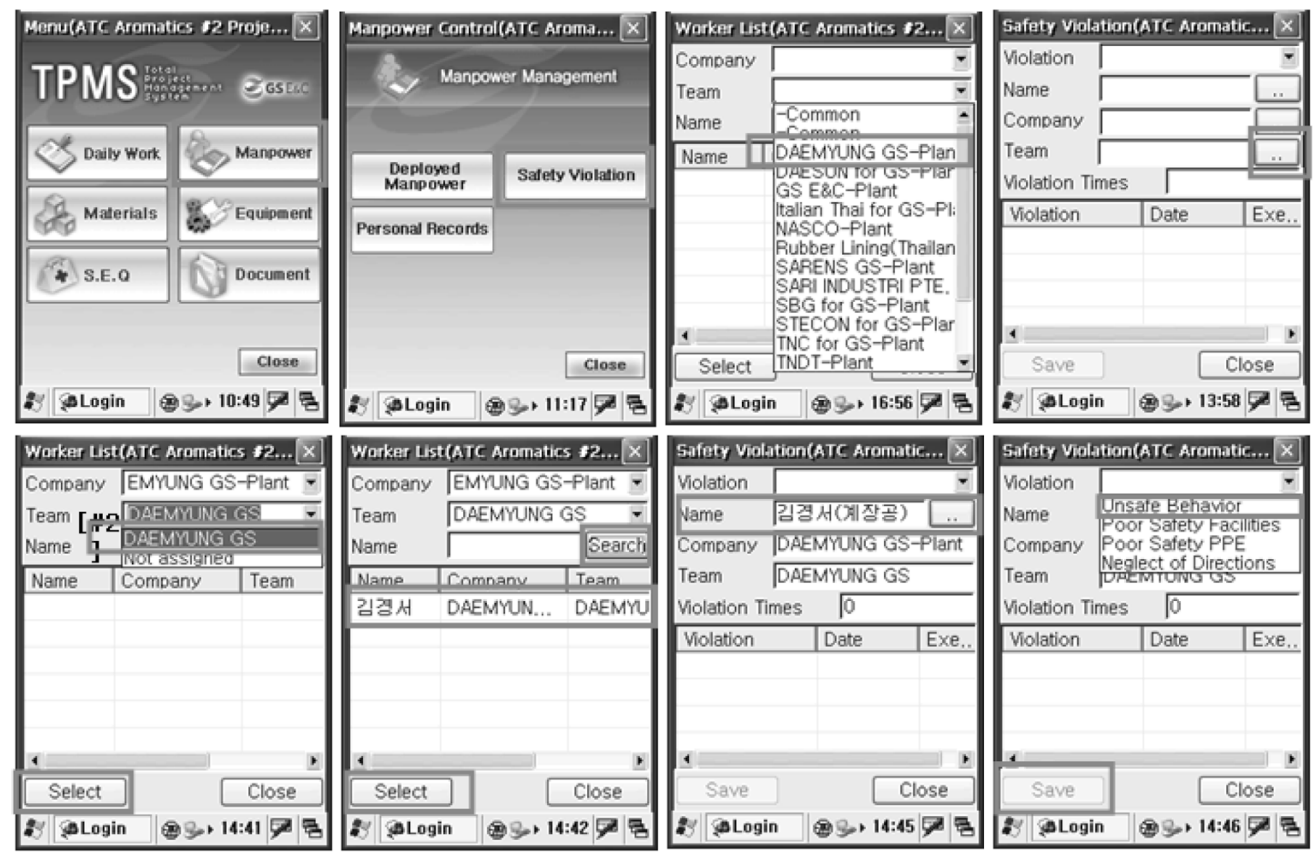

Fig. 9. Safety violation on PDA

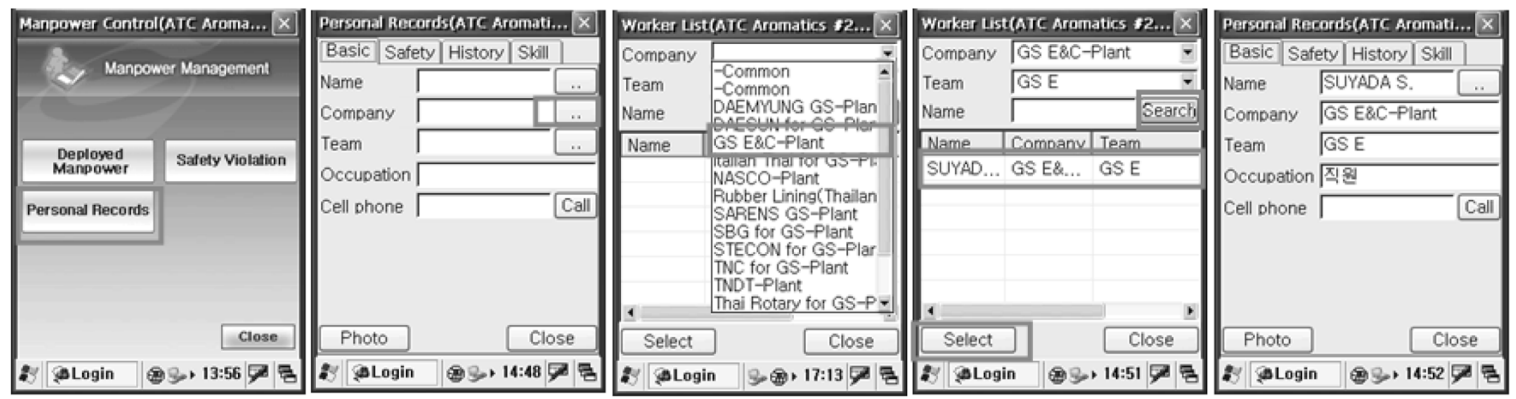

Fig. 10. Personal records on PDA

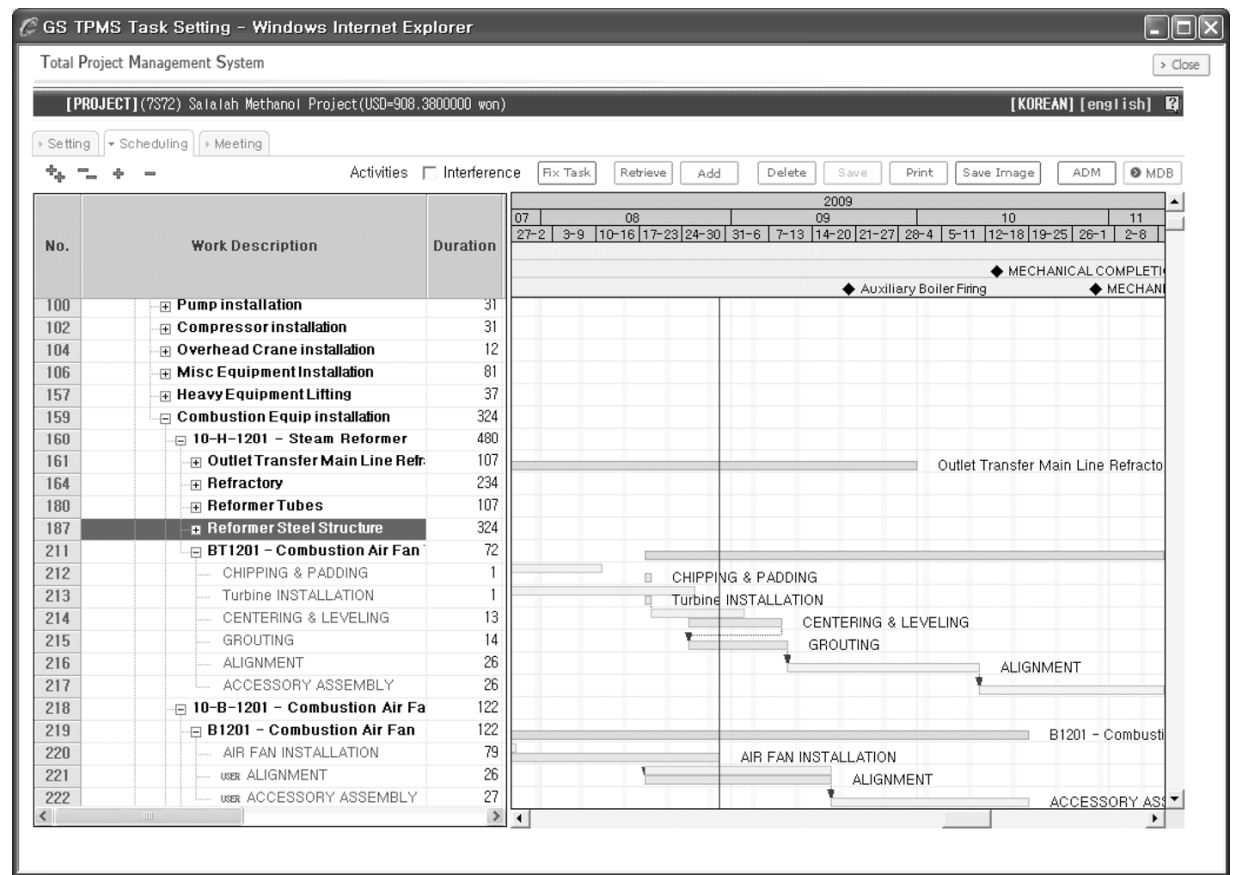

Fig. 11. Example of task Schedule 


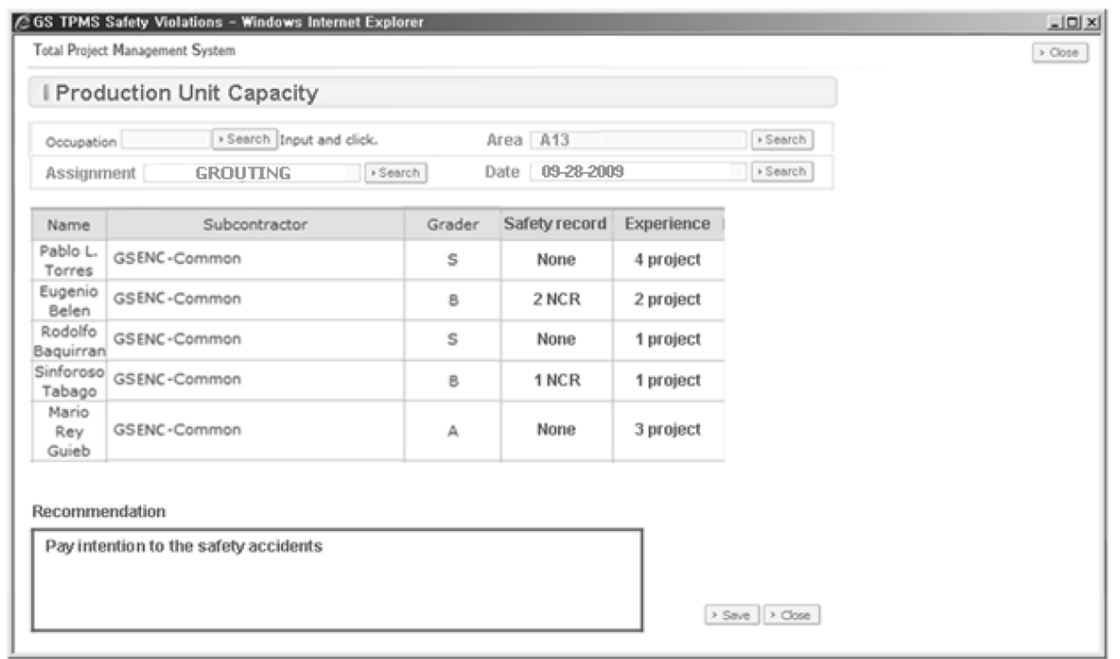

Fig. 12. Example of production unit capacity screen for production planning

site he or she is in as well as previous construction sites. In the Skill tab, they can see the skill type, grade, work site and evaluator for a certain worker.

PDA and RFID technologies can simplify the collection, tracking and managing of workforce information in the field. Data can be retrieved by the users who need the information in determining a production unit's capacity.

\section{System implementation}

Production planning needs to determine assigned loads and a production unit's capacity, and the proposed workforce information database system can provide both. The system also gives balanced views to construction managers and site managers because they have both sides of the information: quantitative (assignment loads) and qualitative (production unit's capacity). The next example demonstrates how to create a production plan.

Contractors or subcontractors set up each work task from a weekly schedule. They can determine which work tasks are done on a given day. Fig. 11 shows an example work task schedule. There are 3 work tasks on September 28: CENTERING and LEVELING, GROUTING, and ALIGNMENT.

Managers then assess the attributes of the work tasks such as the level of work task, difficulty and so on. After assessing, they confirm the figure that is placed on each work task from 1 to 6 as shown in Fig. 3 .

Based on work task assessment, contractors can retrieve a possible production unit from the workforce information database system. Each production unit has detailed information when it registered in the workforce management database system. As shown in Fig. 12, for example, the user can view a suitable production unit based on a unit's level of workmanship, safety records and experience in GROUTING, for instance.

In this example, contractors cannot help but choose the production unit of Pablo L. Torres, because Pablo's team has $\mathrm{S}$ grade, which indicates no accident record and four project experiences.

\section{Discussion}

\subsection{Survey methodology}

It was difficult to validate the effectiveness of the workforce database management system prototype on a full scale. Instead, the authors implemented a survey to assess the system's effectiveness. The authors developed questionnaires to identify the benefits of the suggested system. The questionnaires were distributed to a group of five project mangers and were revised according to the comments from a pilot survey. In constructing the questionnaire, a Likert scaling system was used. The scale is a seven-point rating scale in which the attitude of the respondent is measured on a continuum from highly favorable to highly unfavorable, or vice versa, with an equal number of positive and negative response possibilities and one middle or neutral. The questions related to the system are as follows:

1) Sample question: Does this system help when you perform production planning?

2) Sample question: Does this system help when you perform safety planning?

3) Sample question: Does this system help when you count the number of crew on site?

A total of 91 foremen, superintendents, field engineers, and site managers who have used the proposed system were asked to answer the questionnaire and provide comments. Table 4 shows the survey results using the seven-point Likert scale questions, in which a score of " 1 " corresponds to "Least Helpful" and a score of "7" means "Most Helpful".

\subsection{Benefits from the suggested system}

Benefits from the suggested system have been identified in Table 4 and they are grouped into two categories throughout the survey:

1) Accurate workforce capacity for production and safety planning. In the suggested system, safety, skill and experience information are used for production planning. There is great potential 
Table 4. Survey result on benefits with the proposed system

\begin{tabular}{|c|c|c|c|c|c|c|c|}
\hline \multicolumn{2}{|c|}{ Information } & \multirow{2}{*}{$\begin{array}{c}\text { No. } \\
7\end{array}$} & \multirow{2}{*}{$\begin{array}{c}\begin{array}{c}\text { Production } \\
\text { planning }\end{array} \\
6.1\end{array}$} & \multirow{2}{*}{$\begin{array}{c}\begin{array}{c}\text { Safety } \\
\text { planning }\end{array} \\
6.0\end{array}$} & \multirow{2}{*}{$\begin{array}{c}\text { Time of } \\
\text { Counting }\end{array}$} & \multirow{2}{*}{$\begin{array}{c}\begin{array}{c}\text { Easy to } \\
\text { operate }\end{array} \\
2.5\end{array}$} & \multirow{2}{*}{$\begin{array}{c}\text { Average } \\
5.2\end{array}$} \\
\hline \multirow{4}{*}{$\begin{array}{l}\text { Commercial Building } \\
\text { project } \\
(23 \text { sites })\end{array}$} & Foremen & & & & & & \\
\hline & Superintendents & 6 & 5.8 & 5.5 & 6.4 & 2.8 & 5.1 \\
\hline & Field Engineers & 8 & 6.3 & 6.1 & 6.6 & 3.4 & 5.5 \\
\hline & Site Managers & 4 & 6.4 & 6.2 & 6.1 & 3.0 & 5.4 \\
\hline \multirow{4}{*}{$\begin{array}{l}\text { Residential } \\
\text { project } \\
\text { (31 sites) }\end{array}$} & Foremen & 9 & 6.0 & 5.5 & 6.6 & 2.4 & 5.1 \\
\hline & Superintendents & 8 & 5.9 & 5.2 & 6.7 & 2.1 & 5.0 \\
\hline & Field Engineers & 15 & 6.4 & 5.8 & 6.4 & 3.5 & 5.5 \\
\hline & Site Managers & 9 & 6.1 & 5.5 & 6.2 & 3.1 & 5.2 \\
\hline \multirow{4}{*}{$\begin{array}{l}\text { Civil } \\
\text { project } \\
(14 \text { sites })\end{array}$} & Foremen & 4 & 5.5 & 5.0 & 6.3 & 2.2 & 4.7 \\
\hline & Superintendents & 5 & 5.3 & 5.2 & 6.4 & 2.0 & 4.7 \\
\hline & Field Engineers & 3 & 6.0 & 5.8 & 6.5 & 2.8 & 5.3 \\
\hline & Site Managers & 3 & 5.9 & 5.6 & 6.6 & 2.6 & 5.2 \\
\hline \multirow{4}{*}{$\begin{array}{l}\text { Industrial } \\
\text { project } \\
\text { (8 sites) }\end{array}$} & Foremen & 2 & 6.0 & 6.0 & 6.0 & 3.0 & 5.2 \\
\hline & Superintendents & 4 & 5.8 & 5.2 & 6.4 & 3.3 & 5.2 \\
\hline & Field Engineers & 3 & 5.9 & 5.2 & 6.0 & 3.5 & 5.1 \\
\hline & Site Managers & 1 & 6.0 & 5.0 & 6.0 & 4.0 & 5.2 \\
\hline \multicolumn{2}{|c|}{ Total / Average } & 91 & 6.0 & 5.6 & 6.3 & 2.9 & - \\
\hline
\end{tabular}

(average 6.0, 5.6) when workforce information is used by a contractor in production planning and safety planning. The case study result also showed that the weekly percent plan completion (Ballard 2000) improved by around 6-10\% based on a 4-week moving average;

2) Faster counting of crew on site. An additional benefit in using RFID technology is the reduced time and effort in counting the number of workers. In the traditional approach, each field engineers spends 5 to 20 minutes during the daily head-count. Through the RFID, no other resources are required to count the number of crew members on site. The information can be easily grouped into work divisions or work areas. The time required for processing time cards for employees has been drastically reduced.

\section{Conclusions}

A production plan, which essentially matches capacity with loads, is required in managing construction projects. The capacity of production units (or crews) is dependent on qualitative attributes as well as quantitative capacity. Developing a production plan involves several steps. With quantity takeoff, contractors can calculate assignment loads and match assigned loads appropriately to a production unit. However, gathering and transmitting a production unit's qualitative capacity information is not easy on site.

We addressed this issue by investigating which workforce information can be useful in production/safety planning and control through a survey. The survey showed that four types of information (general personal information, safety records, work experience and level of workmanship) are needed. This paper proposed a prototype database that provides the information on production units' capacity, especially qualitative attributes, to a production planner. The research also demonstrated how the prototype system can be used. The system's effectiveness and efficiency were also tested through a survey.

The survey results showed that the information provided by the prototype system: (1) has high potential (average $6.0,5.6$ ) for use in workforce capacity in production and safety planning respectively; and (2) it reduces time consumed in counting the number of crew on site.

The proposed system contributes to the knowledge and practice of production planning since it elaborates on how qualitative workforce information is defined and managed in a workforce database system. Contractors can easily obtain accurate information about each production unit's capacity, and select the appropriate production unit for each work task.

We expect that the quality of production planning process will be improved by more precise matching of capacity with loads through the suggested process and aided by the workforce database. In the long run, the suggested process and system can contribute to improving productivity as well as planning reliability, which is outside the scope of this research.

\section{References}

Aalami, F. 1998. Using Method Models to Generate 4D Production Models. PhD Thesis. Civil and Environmental Engineering Department, Stanford University, CA, USA.

AbouRizk, S.; Mather, K. 1998. A CAD-Based simulation tool for earthmoving construction method selection, in Proc. of Computing in Civil Engineering ASCE, 39-52.

Adeli, H.; Karim, A. 1997. Scheduling/cost optimization and neural dynamics model for construction, Journal of Construction Engineering and Management ASCE 123(4): 450-458. http://dx.doi.org/10.1061/(ASCE)07339364(1997)123:4(450) 
Ballard, G. 1994. The Last Planner, in Proc. of the Northern California Construction Institute, 22-24 April, 1994, Monterey, California. $8 \mathrm{p}$.

Ballard, G.; Howell, G. 1998. Shielding production: an essential step in production control, Journal of Construction Engineering and Management ASCE 124(1): 11-17. http://dx.doi.org/10.1061/(ASCE)0733-9364(1998)124: $1(11)$

Ballard, G. 2000. The Last Planner System of Production Control. PhD Thesis. School of Civil Engineering, Faculty of Engineering, University of Birmingham, UK.

Ballard, G.; Kim, Y.; Jang, J.; Liu, M. 2007. Roadmap to lean implementation at project level, Research Report 234-11, Construction Industry Institute (CU), Austin, Texas.

Bowden, S.; Dorr, A.; Thorpe, T.; Anumba C. 2006. Mobile ICT support for construction process improvement, Automation in Construction 15(5): 664-676.

http://dx.doi.org/10.1016/j.autcon.2005.08.004

Burgy, C.; Garrett Jr. J. H. 2002. Wearable computers: an interface between humans and smart infrastructure systems, Bauen mit Computern 2002, Bonn, Germany, VDI Verlag, Duesseldorf, Germany. 13 p.

Chen, Z.; Li, H.; Wong, C. T. C. 2002. An application of barcode system for reducing construction waste, Automation in Construction 11: 521-533. http://dx.doi.org/10.1016/S0926-5805(01)00063-2

Choo, H. J. 2003. Distributed Planning and Coordination to Support Lean Construction. PhD Thesis. Department of Civil and Environmental Engineering, College of Engineering, University of California, Berkeley, US.

Ergen, E.; Akinci, B.; East, B.; Kirby, J. 2007. Tracking components and maintenance history within a facility utilizing radio frequency identification technology, Journal of Computing in Civil Engineering ASCE 21(1): 11-20. http://dx.doi.org/10.1061/(ASCE)0887-3801(2007)21:1(11)

Gil, N.; Tommelein, I. D.; Kirkendall, R. L.; Ballard, G. 2000. Contribution of specialty contractor knowledge to early design, in Proc. of the 8th Annual Conference of International Group of Lean Construction, 17-19 July, Brighton, UK. 11 p.

Holm, L.; Schaufelberer, J.; Griffin, D.; Cole, T. 2004. Construction Cost Estimating: Process and Practices. New York: Prentice Hall. 368 p.

Jaselskis, E. J.; Anderson, M. R.; Jahren, C. T.; Rodriguez, Y.; Njos, S. 1995. Radio-frequency identification application in the construction industry, Journal of Construction Engineering and Management ASCE 121(2): 188-196. http://dx.doi.org/10.1061/(ASCE)0733-9364(1995)121: 2(189)

Jaselskis, E. J.; El-Misalami, T. 2003. Implementing radio frequency identification in the construction process, Journal of Construction Engineering and Management ASCE 129(6): 680-688. http://dx.doi.org/10.1061/(ASCE)07339364(2003)129:6(680)

Kim, C.; Kim, H.; Ryu, J.; Kim, C. 2011. Ubiquitous sensor network for construction material monitoring, Journal of
Construction Engineering and Management ASCE 137(2): 158-165.

http://dx.doi.org/10.1061/(ASCE)CO.1943-7862.0000257

Kim, S.; Kim, Y.; Park, C. 2008a. Case studies of the mega projects in applying the lean construction, Journal of American Institute of Constructor 32(2): 33-40.

Kim, Y. S.; Oha, S. W.; Cho, Y. K.; Seo, J. W. 2008b. A PDA and wireless web-integrated system for quality inspection and defect management of apartment housing projects, Automation in Construction 17(2): 163-179. http://dx.doi.org/10.1016/j.autcon.2007.03.006

Kimoto, K.; Endo, K.; Iwashita, S.; Fujiwara, M. 2005. The application of PDA as mobile computing system on construction management, Automation in Construction 14(4): 500-511. http://dx.doi.org/10.1016/j.autcon.2004.09.003

Moon, S.; Yang, B. 2010. Effective monitoring of the concrete pouring operation in an RFID-based environment, Journal of Computing in Civil Engineering ASCE 24(1): 108-116. http://dx.doi.org/10.1061/(ASCE)CP.1943-5487.0000004

Sarma, S.; Engels, D. W. 2003. On the Future of RFID Tags and Protocols. Technical Report, Auto-ID Center, Cambridge, MA. $11 \mathrm{p}$.

Schneider, M. 2003. RFID Technology and its Applications in the Commercial Construction Industry. MS Thesis in Civil Engineering, University of Kentucky, USA.

Song, J.; Hass, C. T.; Caldas, C.; Ergen, E.; Akinci, B. 2006a. Automating the task of tracking the delivery and receipt of fabricated pipe spools in industrial projects, Automation in Construction 15(2): 166-177. http://dx.doi.org/10.1016/j.autcon.2005.03.001

Song, J.; Haas, C.; Caldas, C. 2006b. Tracking the location of materials on construction job sites, Journal of Construction Engineering and Management ASCE 132(9): 911918. http://dx.doi.org/10.1061/(ASCE)0733-9364(2006) $132: 9(911)$

Sucur, M.; Grobler, F. 1996. Construction planning through multi-agent constraint satisfaction, in Proc. of the 3rd Congress on Computing in Civil Engineering, conjunction with A/E/C Systems '96, 17-19 June, 1996, Anaheim, California, 240-246.

Tommelein, I. D.; Ballard, G. 1997. Coordinating Specialists. Technical Report No. 97-8, Construction Engineering and Management Program, Department of Civil and Environmental Engineering, University of California, Berkeley, CA. $10 \mathrm{p}$.

Viana, D.; Mota, B.; Formoso, C.; Echeveste, M.; Peixoto, M.; Rodrigues, C. 2010. A survey of the last planner system: impacts and difficulties for implementation in Brazilian companies, in Proc. of the $18^{\text {th }}$ Annual Conference of International Group of Lean Construction, 14-16 July, 2010, Haifa, Israel, 497-507.

Wang, L.-C. 2008. Enhancing construction quality inspection and management using RFID technology, Automation in Construction 17(4): 467-479.

http://dx.doi.org/10.1016/j.autcon.2007.08.005

Sang-Chul KIM. Assistant Professor at the Department of Architectural Engineering, Hanbat National University, Daejeon, South Korea. He is a member of Korea Institute of Construction Engineering and Management (KICEM). His research interests are Earned Value and its application to construction field, construction management system to fit to construction employees.

Yong-Woo KIM. Associate Professor, P.D. Koon Endowed Professor of Construction Management, College of Built Environments, University of Washington, Seattle, WA. He is a member of American Society of Civil Engineers (ASCE). His research interests include lean construction and supply chain management. 